\title{
A Quick Review to Understand Micro Grid System: System Architectures, Modes and Challenges
}

\author{
Mohd Fahmi Abdullah ${ }^{1}$, Norzanah Rosmin ${ }^{2 *}$, Aede Hatib ${ }^{3}$, Siti Maherah Hussin ${ }^{4}$ \\ ${ }^{1,2 * 3}$ Centre of Electrical Energy System (CEES), POWER Department, School of Electrical, Engineering Faculty, \\ Universiti Teknologi Malaysia, Johor, Malaysia,mmfahmi234@gmail.com, norzanah@utm.my, \\ maherah@utm.my \\ ${ }^{4}$ School of Education, Engineering Faculty, Universiti Teknologi Malaysia, Johor, Malaysia, aede@utm.my
}

\begin{abstract}
This paper highlighting the main issues in the new era of distributed generation closed to the distribution network or popularly known as Micro Grid (MG) system, in the electrical power system network. A MG is particularly a section of the large power distribution system that comprises distributed or co-generation, energy storage system and loads. In this paper, review on the system architecture, operational modes and also the control challenges on the demand response in MG system is demonstrated. The gathered information is compressed and then written in brief to be used as a quick guide for the new researchers or newcomers in this field. All important elements in the MG will be explained in brief as well as comparing the worthy outcomes and the potential fields of research in particular in terms of energy flow control that would enhance practical use of MG system and its elements.
\end{abstract}

Key words: Micro grid, grid connected, stand alone, islanded, demand response, energy storage.

\section{INTRODUCTION}

The use of renewable energy sources (RESs) is a significant lever for decarbonizing the electric power sector and reducing the effects of climate change to the environment [1]. Nowadays, RES is widely used to provide an alternative to or an enhancement of the conventional grid network system, and typically developed in small-scale capacity. Such RES that also typically supported with storage technologies is known as distributed energy resource (DER) system, which usually in the capacity of $1 \mathrm{~kW}$ to $10,000 \mathrm{~kW}$ [2]. On the other hands, DER also has defined as small-scale units of local generation connected to the grid at distribution level [3].

DERs are usually numerous, installed closed to the loads or customers in small-scale. Essentially, DERs act as central energy commodities and are often connected to the network on a 'connect-and-forget' basis. Hence, to allow the DERs to penetrate and seemed visible in the energy markets, smart grid (SG) technology is an option as the key to efficient use of DERs. In [4], smart grid (SG) was defined as "an electricity network that can intelligently integrate the actions of all users connected to it - generators, consumers and those that do both - in order to efficiently deliver sustainable, economic and secure electricity supplies." Therefore, SG seems can encourage the active participation and decision-making of consumers as well as to establish the operating environment in which both utilities and energy users influence each other. Users can control utilities in SGs by incorporating DERs such as photovoltaic (PV) modules or point-of-use energy storage and responding to price signals. In addition, utilities can enhance reliability by providing demand response programs, adding distributed generation or energy storage at substations, and automated grid control. Nowadays, the use of RESs in the SG system has increased in recent years, as it provides alternative options to feed the world's energy appetite which allow for consideration of the environmental impact and other social and economic factors. Some studies have mentioned that this technology can provide reliable and comparatively low-cost electricity service [5-7].

In SG system, it may comprise several micro grid (MG) systems. Different to SG, MG is an electrical system that includes numerous DERs, energy storages and customers' loads that can be operated in parallel with the small grid or even with wider utility grid, self-governing power system, to enable the grid to exchange power over a single coupling point, called the Point of Common Coupling (CCP) [8]. With MG, system reliability and efficiency can be increased with reduced transmission length yet provide simpler integration of RES systems. Figure 1 shows an example of MG system that consists of its three main components; various RESs (solar, wind and diesel generators), battery energy storage system (BESS), and loads (AC and DC loads). Here, it can be observed that electricity generations are placed close to the loads, to enhance the MG's development of reliability, efficiency, and quality of power support [9].

Generally, MG can work in 2 different modes; grid-connected and the stand-alone (autonomous) mode. In grid-connected mode, all related feeders will be supplied electrically through the utility grid [11]. In this mode, to achieve maximum operating benefits, MG will regulate the power balance between supply and demand (through a buying or selling process with the main grid) [12]. In fault situations, MG will 
be immediately isolated and acts as a stand-alone device. Conversely, during stand-alone (autonomous) mode, MG is disconnected from the main grid by opening the feeder's static switch.

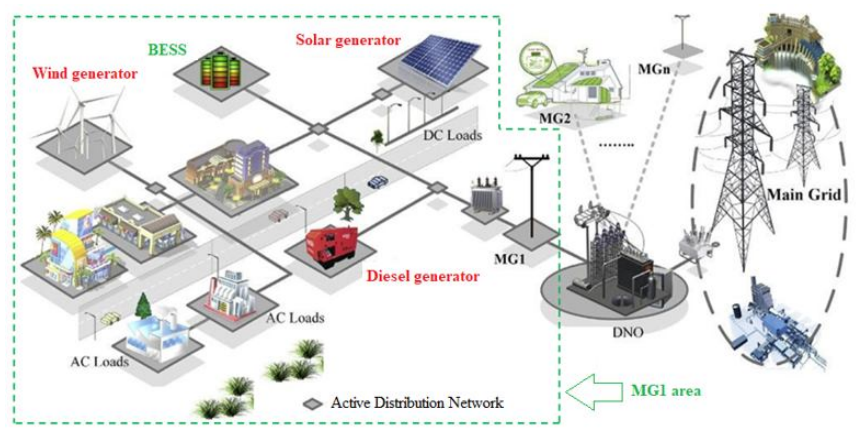

Figure 1: Micro Grid (MG) System Components [10].

Therefore, the micro-source network now supports the remains feeders [11]. In both modes however, the role of energy storages are very significant for energy backup, in particular to enhance the power fluctuations and power quality between the RESs and loads sides, that may effecting the reliability and stability of the MG's operational system. In addition, power from RESs is always variable and fluctuates, instead the issues of nonlinear load changes from the demand sides. In Malaysia, SG or MG is still very new. So far, by the time this paper is written, at the end-user level, the application changes only have been introduced in metering and monitoring system. Smart energy management system (EMS) in SG, or even in MG system, is still far lack. Hence, detailed study on the MG management system, which can optimizing the MG operational strategy that focuses to the RESs, energy storages and demand responses management in Malaysian context is an urgent attention as this strategy is projected may offer more environmental friendly and cheaper electricity price [13]. Situations in both modes also need some attentions for a smarter MG's architecture.

\section{SIGNIFICANCE OF REVIEW WORK}

RE distributed generator (DG) units are the base of MGs and located at or near the point of use. To convert the energy into grid-compatible ac power, most of the DG technologies require a power electronics interface that assisted with sophisticated control system, that able to convert and control the power flow from one level to another. In Malaysia scenario, PV system has a great potential to be selected as promising DG system. In previous, feed-in-tariff (FiT) was used as incentive for the PV penetration, and since 2019, net-energy-metering (NEM) scheme was introduced to increase the national energy target from RE. Using NEM, energy produced from the solar PV system installed will be consumed first, and any excess to be exported and sold to the distribution licensee (such as TNB /SESB ) at the prevailing displaced cost prescribed by the Energy Commission. The introduced NEM not consider energy storage system in the NEM scheme. Hence, study on the smart energy management system (EMS) in residential MG system relating the RES, demand response and energy flow control is very necessary to be executed. To achieve optimum operational MG, with promising minimum electricity costs (from RES and customer sides), so far, no standard guideline has been established or imposed. Hence, other than giving compact information on the MG's architecture and its operational modes, this review work also may provide the information on how to control the energy flow by optimizing the MG operational strategy that focuses to the solar PV as RES, energy storages and demand responses management, to minimize the electricity price.

\section{SMART GRID (SM) VERSUS MICRO GRID (MG) SYSTEM}

To understand the concept of MG, it is important to understand what the definition of a smart grid (SG) system is. SG has been defined as an electrical network that incorporates a range of technologies, such as distributed generation, energy storage systems (ESS), and communication systems [14], as depicted in Figure 2. SG has close cooperation of measuring equipment to determine consumer power demand, resulting in increased productivity and efficiency overall of the power grid [15]. Essentially, SG is not a new concept, but is a new technology that transforming the grid control and creating a platform for revolution of the traditional electricity grid functions. SG uses the emerging technology to encourage energy and cost-efficiency [16] which can predict, measure and respond automatically to fluctuations in supply and demand, beside offers the potential for greater supply protection through performance. The potential for flexibility is much greater when combined with the roll-out of smart meters, as consumers change their own real-time requirements and accelerate the introduction of renewable energy into the grid [17].

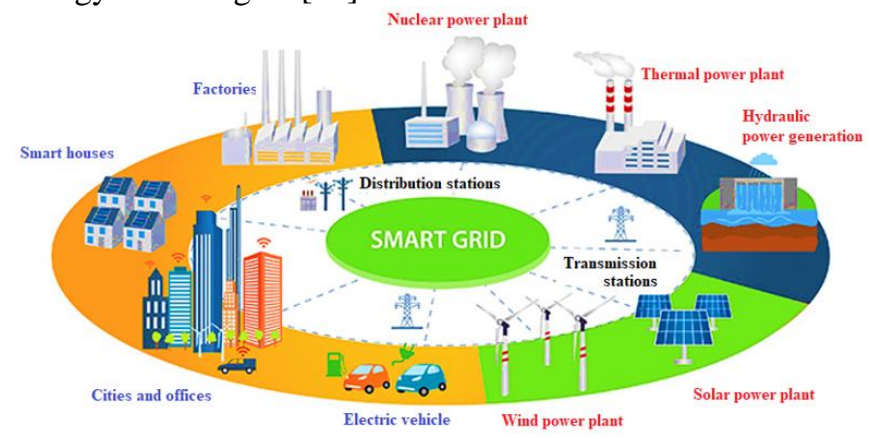

Figure 2: Smart Grid (SG) System [18]

Meanwhile, MGs which are elements in the SG system (as shown in Figure 1) are implemented to address the network shortcomings, to incorporate the power system components into smaller scales. MG is a distributed power grid that consisting of numerous small sources that capable of running parallel and independently to the main grid [19]. Its main objective is to achieve a reliable and efficient supply of electricity and to ensure a higher quality electrical service, while making the service safer and more sustainable, especially in the urban and rural areas. MG helps network operators to control the generation and consumption more 
flexibly. Therefore, energy management is a critical factor in MG system since it has multiple loads as well as production units. For safety and reliability factors, MG can operate the energy market in both grid-connected and stand-alone (autonomous) [20]. Figure 3 shows a small MG system development for a residential area that uses PV module as an energy source, battery as ESS, inverter as power converter that change the DC signal into AC signal and bidirectional meter as the device that recording the energy supplied or consumed by the consumer [21]. Summary for comparison between SG and MG is given in Table 1. From the table, it can be observed that SG system is more complex than MG system and requires more sophisticated control system due to its size and complexity elements.
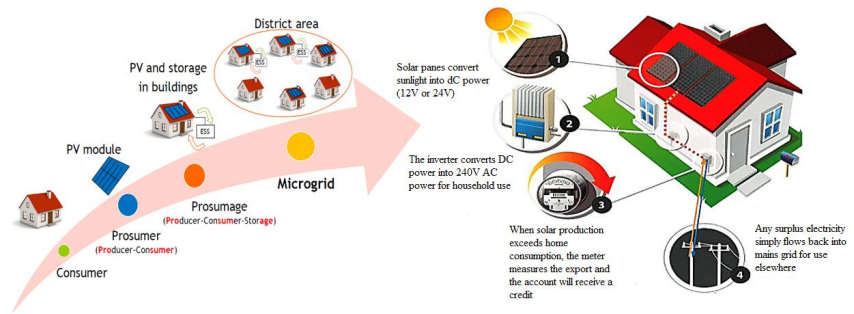

Figure 3: Office area that used energy from PV system Micro grid (MG) System Development [21]

Table 1: Micro Grid (MG) Versus Smart Grid (MG) [17]

\begin{tabular}{ll}
\hline \multicolumn{1}{c}{ Smart Grid (SG) } & \multicolumn{1}{c}{ Micro Grid (MG) } \\
\hline Digitization & Mechanization \\
\hline Two-way real-time communication & One-way communication \\
\hline Distributed power generation & Centralized power generation \\
\hline Dispersed network & Radial network \\
\hline Large volumes of data involved & Less data involved \\
\hline Many sensors and monitors & Small number of sensors \\
\hline Great automatic monitors & Less or no automatic monitoring \\
\hline Automatic control and recovery & Manual control and recovery \\
\hline Prone to security and privacy issues & Less security and privacy concerns \\
\hline Adaptive protection & Human attention to system disruptions \\
\hline Use of storage systems & Simultaneous production and consumption of energy/electricity \\
\hline Extensive control system & Limited control \\
\hline Fast response to emergencies & Slow response to emergencies \\
\hline Vast user choices & Fewer user choices \\
\hline
\end{tabular}

\section{MICRO GRID (MG) ARCHITECTURE}

Micro grid (MG) electrical architecture is basically determined by the application, existing infrastructure, and customer-oriented needs. As mentioned previously, MG structure consists of several types of distributed energy sources (DER) such as solar panels, wind turbines, micro turbines, and thermal power plant, each in the form of distributed generation (DG), including energy reserves from battery (Distributed storage, DS). MG system is typically operating at a low voltage level distribution system and can operate either in grid-connected or stand-alone (autonomous) mode [22].

MG architecture is generally divided into three categories which are AC, DC, and hybrid micro grid system [23]. Among these three MG architectures, AC MG is easier to design and implement by utilizing the existing $\mathrm{AC}$ network infrastructure such as distribution, transformers, and its existing protections system [24]. For AC micro grid architecture, it is the most popular structure and commonly used for MG studies and implementations. Example of AC
MG can be illustrated in Figure 4 [24], where the distributed generation (DG), energy storage and the mixed $\mathrm{AC}$ and $\mathrm{DC}$ loads are connected via an AC bus. However, for the DC source, energy storage and load, DC/AC inverter is required when connected to AC bus. Conversely, in DC MG architecture, the $\mathrm{MG}$ components are connected via a DC bus, as shown in Figure 5. In this architecture, AC/DC converter is used to convert the $\mathrm{AC}$ power from the $\mathrm{AC}$ source and $\mathrm{AC}$ loads. Compared to AC MG, DC MG provides less power loss since it only requires one-way power conversion to be connected to DC bus. Besides that, DC MG also has better system stability due to lack of reactive power compensation problem, unlike in AC system. Due to this, DC MG has better system efficiency, less expensive and smaller in size compared to AC and hybrid MG architectures [25]. On the other hands, in hybrid AC-DC MG architecture, this architecture attempts to utilize the benefits of both $\mathrm{AC}$ and $\mathrm{DC}$ concepts to improve its system efficiency. Hybrid MG combines both $\mathrm{AC}$ and DC MGs regardless in terms of $\mathrm{AC}$ or DC sources, energy storages, loads and distribution grid systems. Energy transfer between AC and DC sections are always tried to be minimized to avoid conversion loss. The interfacing converters are used to provide active power support to both sections and reactive power support to the AC system [25].

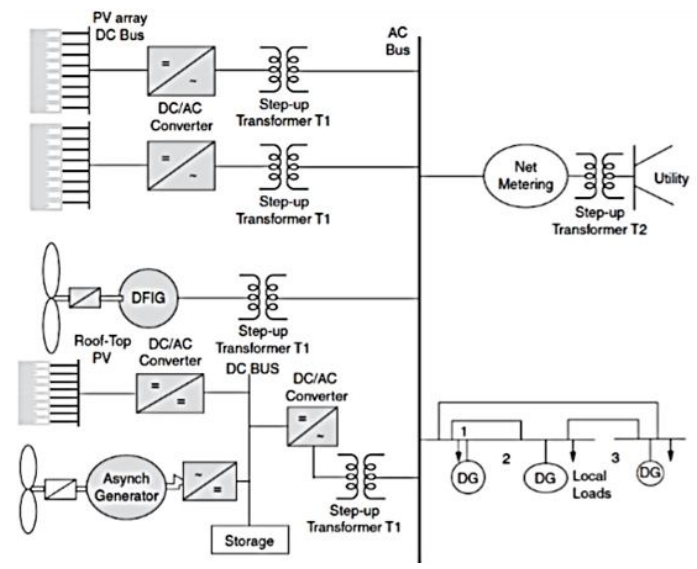

Figure 4: AC Micro Grid Architectures [26]

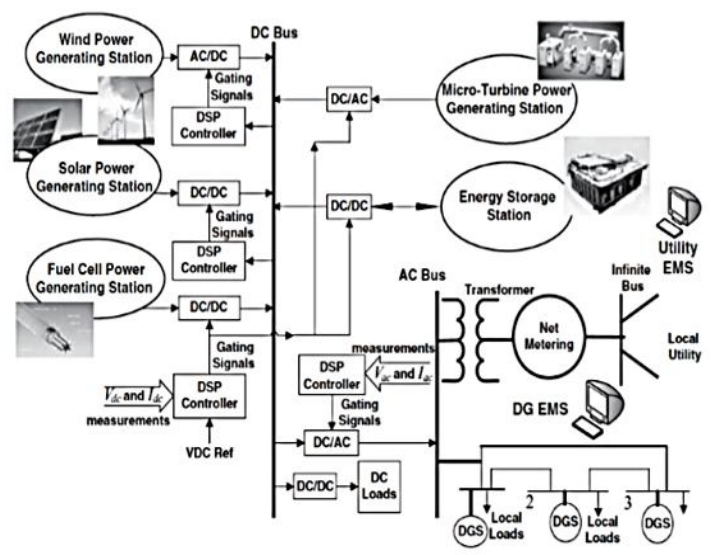

Figure 5: DC Micro Grid Architectures [26] 


\subsection{Distribution Generation (DG)}

Distributed generation (DG) has gained its attraction by providing positive support benefits. However, an inappropriate planning decision on the DG side may manifest the impacts of DG allocation negatively. Determination of appropriate DG size and placement of DG is important, to maximize overall system efficiency and to ensure stable and reliable operation of power distribution network. Generally, distribution systems are designed as radial and power flows unidirectional from transmission network to distribution areas. The introduction of DG into the network changes the characteristics of the distribution system. Integration of a significantly large amount of DG may causes operational conflicts on the distribution system [27]. This then could alter the active and reactive flows of power and this inversion of flow may causes overvoltage to the network [28]. Beside penetration level, location-specific value of DG also plays a significant role for network reliability and stability [29]. No relief or only partial capacity relief of the network can be achieved by DG sources for inappropriate selection of DG sites [30]. In the context of power flow control in MG system, DG units can be grouped into three-unit types; dispatchable energy (power output can be regulated), non-dispatchable (power output cannot be adjusted) and hybrid unit, as shown in Figure 6 [31].

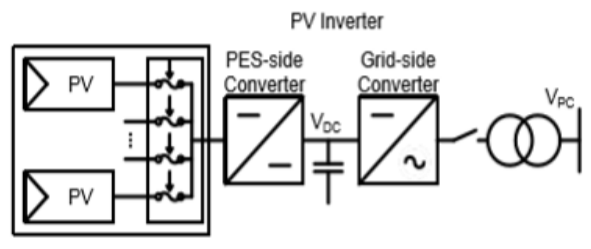

(a) Non-dispatchable

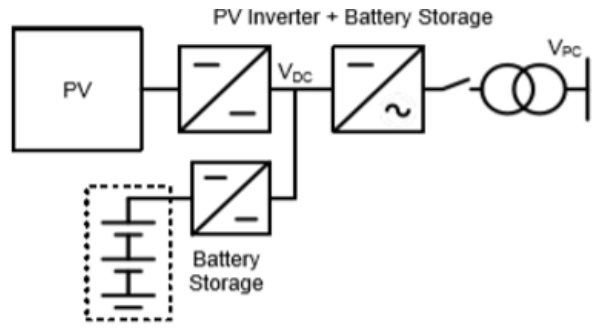

(b) Dispatchable

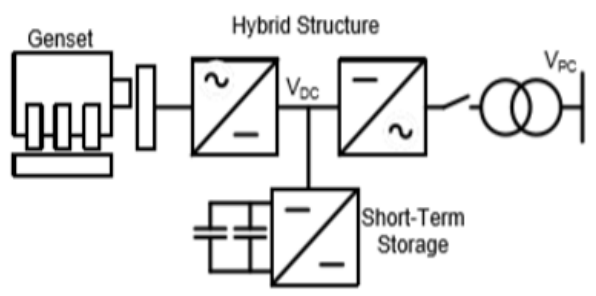

(c) Hybrid

Figure 6: Power Flow Control Configuration in MG System [31]
In dispatchable energy unit, output power setting is set externally using supervisory control such as automatic voltage regulator (AVR). Meanwhile, in non-dispatchable energy unit, output power is set based on the maximum power that can be generated using maximum power point tracking (MPPT) concept [32]. The non-dispatchable energy unit however can be converted into dispatchable energy units using additional energy storage systems and power electronic circuit (dc-dc-ac converter) [33]. To provide faster response, electronic converters can be used to limit the short circuit contribution not less than $200 \%$ from the rated current and able to prevent damage due to the current's surge [30]. Stability of MG operational system can be setting the loads connected to the network, especially on non-critical loads [31].

\subsection{Energy Storage System (ESS)}

Energy storage system (ESS) has been considered within the design of the energy grid since long time ago, but it has had limited relevance due to the factors of high cost. Also, ine $\square$ ciency of many storage systems have undermined their value and functionality [34]. Additionally, existing perceptions of storage as little more than a bank to assist generators to balance the loads over time fails to capture the true potential of energy storage technologies [35]. Therefore, improvements in smart grid designs and its storage technologies could present unique opportunities to challenge the conventional model. New technologies for ESSs that having the capability to reduce and smooth the peaks power are crucial elements in the future power system network. Great ESSs can be the solution to fix the aging power grid, bridging the gaps between the utilities and customers' demands. They have become a critical tool for increasing consumers' comfort, reducing electricity bills, and earning revenue. The storage device allows the consumer to not only store energy for a longer duration of time but also save the consumer's money by charging the storage devices during off-peak hours when the price is low and uses them during peak hours [36]. This increasing importance of energy storage devices has forced the researchers to put great effort into achieving higher efficient and cost-effective storage device. However, there are many other factors associated with the energy storage devices, for instance in terms of energy storage capacity (MWh), power capacity (MW), device and maintenance costs.

Besides, the charging and discharging process of the storage devices requires adequate control strategies to perform reliable operation of grids even during the peak demand [37]. Consumers may reduce the energy consumption of thermal loads such as air conditioners, water chillers, and water heaters, which results in saving the electricity during peak hours. In Table 2, comparison on the technical characteristics of electrochemical type of energy storage (ES) technology is given [38]. Among all, battery is the most widespread and oldest of all the ES technologies [39][40]. This electrochemical device uses chemical energy to deliver energy in the electrical form by undergoing electrochemical 
reactions. When designing a battery storage system in an MG system, numbers of requirement must be considered including the technical, economical, and environmental points of view. In an MG application, combining renewable energies (which have an intermittent energy profile) with energy storage systems, may improve the reliability and stability of the energy supply for extended periods [41]. Energy storage such as battery storage technologies is manufactured in a variety of sizes and chemistries depending on their applications. In many literatures, the pros and cons between the different types of batteries are compared for smart grid requirements including the size, efficiency, cycle life, and cost [42].

Table 2: Comparison of technical characteristics of electrochemical type of battery storage technology [43]

\begin{tabular}{|c|c|c|c|c|c|c|c|c|}
\hline & \begin{tabular}{|c|} 
Specific \\
energy \\
$(\mathrm{Wh} / \mathrm{kg})$ \\
\end{tabular} & $\begin{array}{l}\text { Specific } \\
\text { power } \\
\text { (W/kg) }\end{array}$ & $\begin{array}{l}\text { Efficiency } \\
\text { (\%) }\end{array}$ & $\begin{array}{c}\text { Self- } \\
\text { discharge } \\
(\% / \text { day }) \\
\end{array}$ & $\begin{array}{l}\text { Life } \\
\text { cycle }\end{array}$ & $\begin{array}{l}\text { Power } \\
\text { cost } \\
(\$ / K W)\end{array}$ & $\begin{array}{c}\text { Energy } \\
\text { cost } \\
(\$ / \mathrm{kWh})\end{array}$ & $\begin{array}{l}\text { Power } \\
\text { rating } \\
(\mathrm{kW})\end{array}$ \\
\hline $\begin{array}{l}\text { Sodium } \\
\text { Sulfur (NaS) } \\
\text { battery }\end{array}$ & $150-240$ & $150-230$ & $75-90$ & 0 & 2500 & $\begin{array}{c}1000- \\
3000\end{array}$ & $300-500$ & $50-34000$ \\
\hline $\begin{array}{l}\text { Sodium } \\
\text { Nickel } \\
\text { Chloride } \\
\text { (NaNiCI2) } \\
\text { battery }\end{array}$ & $100-120$ & $150-200$ & $80-950$ & 0 & $>2500$ & $150-300$ & $100-200$ & $50-8000$ \\
\hline $\begin{array}{l}\text { Vanadium } \\
\text { Redox Flow } \\
\text { Battery } \\
\text { (VRFB) }\end{array}$ & 10-25 & 166 & $75-85$ & Low & 12000 & 600-1500 & $150-1000$ & $30-3000$ \\
\hline $\begin{array}{l}\text { Zinc } \\
\text { Bromine } \\
\text { flow battery } \\
(\mathrm{ZnBr})\end{array}$ & $30-50$ & 45 & $65-75$ & Low & $>2000$ & $700-2500$ & $150-1000$ & $50-2000$ \\
\hline $\begin{array}{l}\text { Lithium ion } \\
\text { (Li-lon) } \\
\text { battery }\end{array}$ & \begin{tabular}{|l|}
$75-200$ \\
\end{tabular} & $\begin{array}{c}150- \\
315\end{array}$ & $85-98$ & $0.1-0.3$ & $\begin{array}{l}1000- \\
10000\end{array}$ & $175-4000$ & $500-2500$ & $0-100$ \\
\hline $\begin{array}{l}\text { Lead acid } \\
\text { battery }\end{array}$ & $30-50$ & $75-300$ & $70-90$ & $0.1-0.3$ & $\begin{array}{c}500- \\
800\end{array}$ & $300-600$ & $50-200$ & $0-20000$ \\
\hline $\begin{array}{l}\text { Nickel } \\
\text { Cadmium } \\
\text { (NiCd) } \\
\text { battery }\end{array}$ & 50-75 & $\begin{array}{c}150- \\
300\end{array}$ & $60-70$ & $0.2-0.6$ & $\begin{array}{c}2000- \\
2500\end{array}$ & $500-1500$ & $800-1500$ & $0-40000$ \\
\hline $\begin{array}{l}\text { Super } \\
\text { Capacitor }\end{array}$ & 5-20 & $\begin{array}{l}500- \\
5000\end{array}$ & 95-98 & $20-40$ & $\begin{array}{l}>50 \\
000\end{array}$ & $100-300$ & 500-3000 & $0-300$ \\
\hline
\end{tabular}

\subsection{Demand Response (DR)}

Demand Response (DR) can be defined as the changes or adjustments done by end-use clients or customers to reduce electrical energy consumption by changing their normal behavior when use energy with intention to reduce their electricity bills over time. In other words, DR can also be defined as the inducement compensation designed to encourage lower electricity use at times of high wholesale market prices or when system reliability is risked [44]. DR includes all intended electricity consumption shape modifications by end-use clients or customers that are anticipated to alter the hours of energy used, level of instantaneous need or demands, or overall electrical energy consumption [45]. There are three general actions that performed by consumers [44], where each of these actions involves cost and measures taken by the consumers. For the first consumers response, consumers can reduce their electricity usage by reducing the load usage during critical peak periods (when prices are high), without changing their consumption pattern during other periods. This option however will involve a temporary loss of comfort. This response is achieved, for instance, when thermostat settings of heaters or air-conditioners are temporary changed [46]. Secondly, consumers may respond to high electricity prices by shifting some of their peak demand operations to off-peak periods, as an example, they shift some household activities like dishwashers, pool pumps to off-peak periods. The residential consumers in this case will bear no loss and will incur no cost. However, this will not be the case if an industrial customer decides to reschedule some activities and rescheduling costs to make up for lost services are incurred. Meanwhile, for the third response that can be done by consumers is by using their own on-site generation system [47]. Consumers who generate their own power may experience no or very little change in their electricity usage pattern; however, from utility perspective, electricity use patterns will change significantly, and demand will appear to be smaller.

\section{MICRO GRID OPERATIONAL MODE}

Micro grid (MG) requires several distributed generation resources, loads and energy storages to enable the grid to exchange power over a single coupling point, called the point of common coupling (PCC) [48]. The idea of bringing electricity generation closer to the loads is to enhance MG's development of reliability, efficiency, and quality of power support [49]. MG can work in two different modes; grid-connected and the stand-alone (autonomous) mode [50] [69]. From the executed study, it has been found that there are seven papers [51-58], that have been worked on these MG's modes, as listed in Table 3. From the table, it can be observed that, mostly research work has been focused either in grid-connected or stand-alone mode. No study has found working on both modes. In Figure 7, the basic diagram for grid-connected and stand-alone mode is shown. In grid-connected mode as shown in Figure 7(a), all feeders will be supplied electrically through the utility grid [59] when the static switch is closed. In this mode, to achieve maximum operating benefits, MG will regulate the power balance between supply and demand (through a buying or selling process with the main grid) [60]. If the power system faults, MG will be immediately isolated from the main grid and acts as a stand-alone device, as shown in Figure 7(b). During this time, the static switch is opened. As a result, the DG systems will be disconnected from the main grid, whereby the micro-source network (DGs) now supports the remains feeders [50].

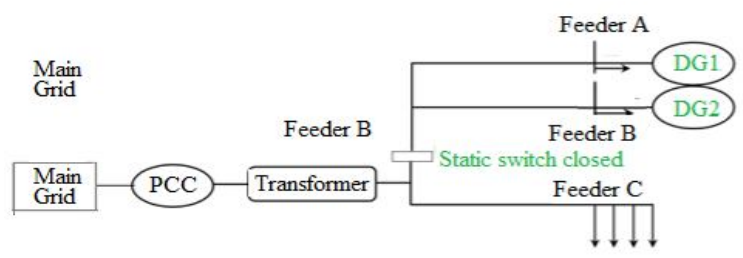

(a) 


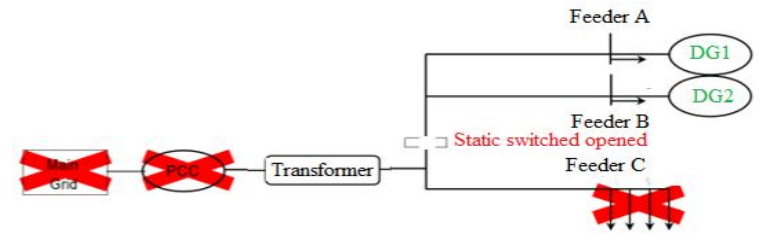

(b)

Figure 7: (a) Grid-connected mode [59], (b) Stand -alone mode [50]

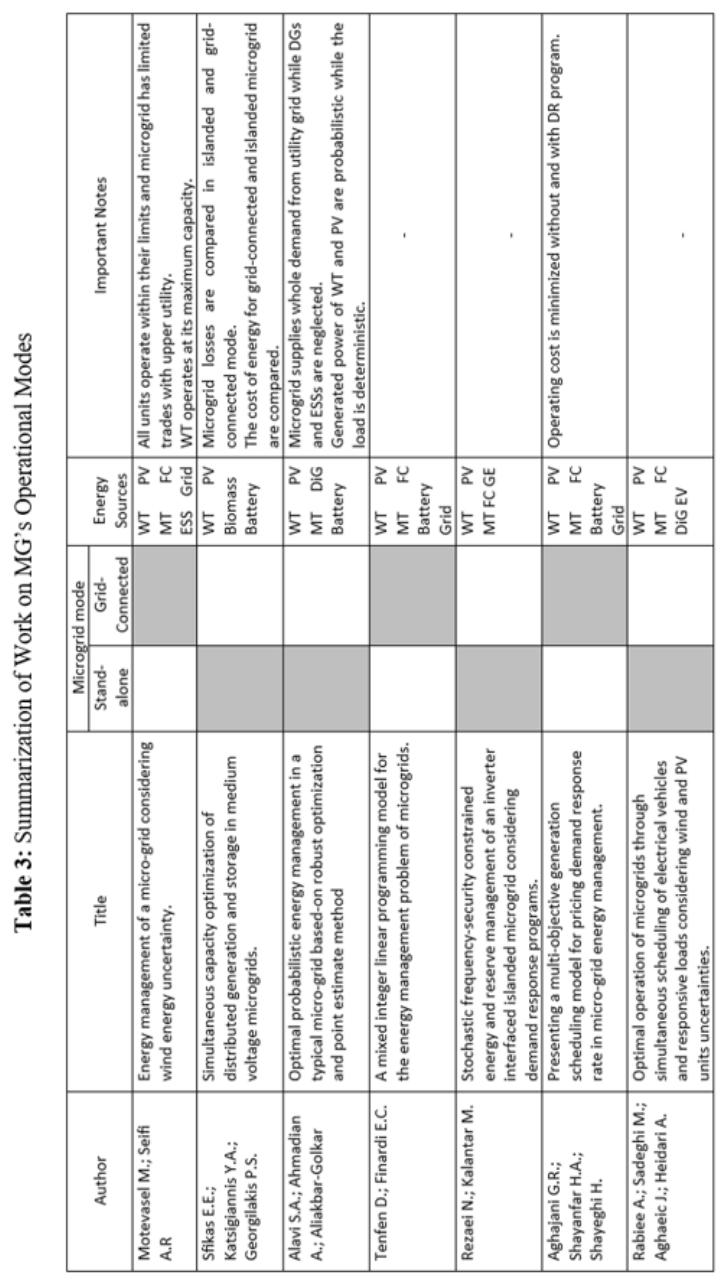

\section{RESEARCH ON MG'S ENERGY MANAGEMENT AND CONTROL}

Another comprehensive study has been executed on the management and control strategies that have been imposed or proposed in MG system. As mentioned, This time, focus has been prioritized in determining the energy source type, energy management system (EMS) approach, control strategies adopted and the involvement of demand response in the MG system. From the study, it has been found that there are eleven papers [61-71] have strong connections to the searched key points. As the results, summarization on this work is demonstrated in Table 4. From the cited references, it can be observed that, mostly, aim of the executed research has been set on to minimize the operation cost of MG while ensuring stable electricity supply to the demand side.
Based on the summarization that has been given in Table 3 and Table 4, it can be seen that the DG considered in the previous study are mostly considered solar photovoltaic and wind energy as the RES, in both grid-connected and stand-alone (autonomous) mode MG system. From Table 4 itself, in terms of EMS and its control, double-layer approach seems as the most popular ones among the reported works. However, the type of fixed and transferrable loads is varying, depends on the studied system. Hence, there are numbers of alternative approaches that can be studied under second layer approach, for instance proposing the load-shape management e.g. load shifting, valley filling, peak clipping, flexible load shape, and etc. Meanwhile, for the RES side, where the first layer approach is imposed, most of the works considered were considering RES such as solar PV, wind, fuel cell, microturbine and ESS. No standard equations or algorithm have been demonstrated on how this RESs are scheduled or optimized. Hence, there is a need to explore on the optimization operation strategy potential of MG model that relating the optimal RES management system based on the cheapest cost, but yet able to give continuous supply to demands response, as this strategy is projected may offer more environmentally friendly and cheaper electricity price [60][72].

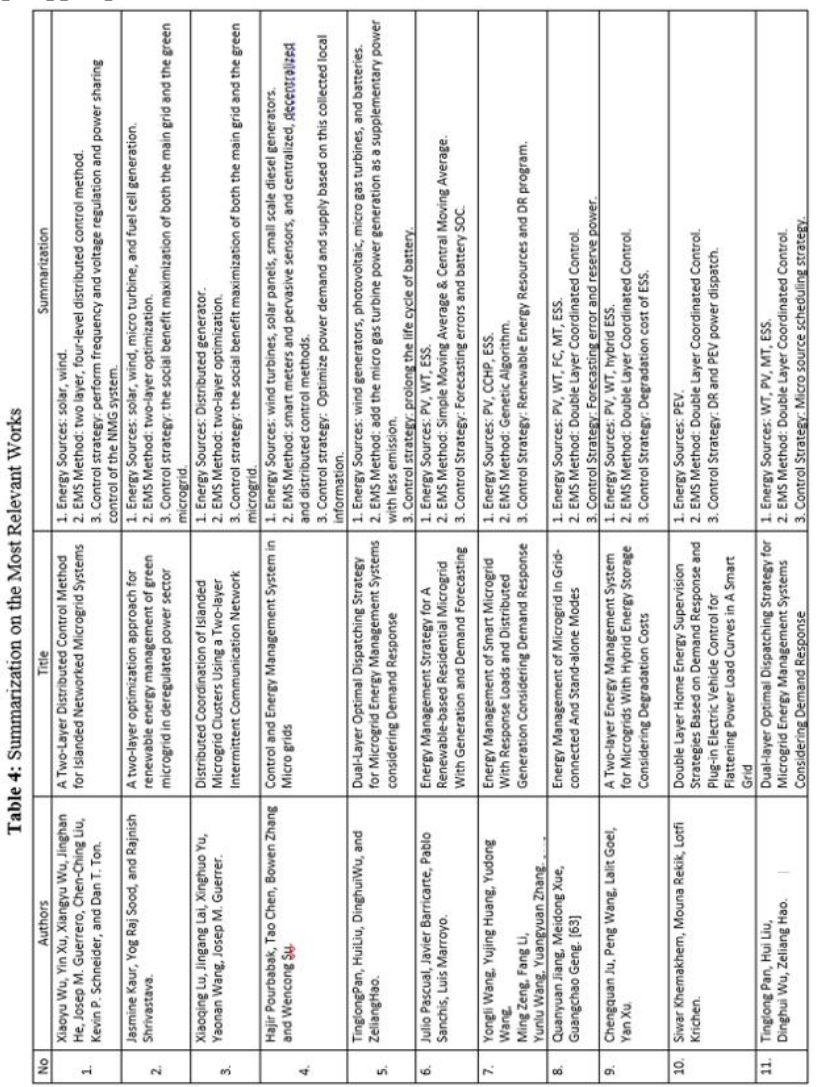

\section{CONCLUSION}

The quick review on the MG system on its definition, architecture, operational modes, and the EMS control challenges in terms of demand response from the load side 
has been demonstrated very briefly. For further works, there are so many area can be focused for the sake of enhancing the technical and techno economics assessments of the MG system, for instance in terms of national policy and incentives, rules \& regulations, guideline \& standards, the safety, capability and reliability of the generation, transmission and distribution smart grid control, internets of things (IoT) in the communication and automation control system, and etc. Demand response is very significant to be regulated and controlled appropriate with the available RES. It is also important to study the behavior or response towards the critical transition period when islanding occurs for stable operation of a microgrid.

\section{ACKNOWLEDGEMENT}

The authors would like to thank the Ministry of Higher Education of Malaysia for the financial funding of this project under Q.J130000.3551.06G65 and ICF (4S142), the Research Management Centre (RMC) of Universiti Teknologi Malaysia, Centre of Electrical Energy Systems (CEES), School of Electrical Engineering, UTM, UTM for their support for the research management.

\section{REFERENCES}

1. Core Writing Team, R.K. Pachauri and L.A. Meyer (Eds.). IPCC 2014: Climate Change 2014, Synthesis Report, Geneva, Switzerland, 151 pp, 2014.

2. N. Phuangpornpitaka, S. Tiab. Opportunities and Challenges of Integrating Renewable Energy in Smart Grid System, Energy Procedia 34, pp. 282 - 290, 2013. https://doi.org/10.1016/j.egypro.2013.06.756

3. ARENA, What are distributed energy resources and how do they work? , Distributed energy resources, 15 March 2018.

4. Janaka Ekanayake and etal. Smart Grid: Technologies and Applications, John Wiley and Sons, Ltd, United Kingdom, 2012.

5. Cosentino V, Favuzza S, Graditi G, Ippolito MG, Massaro F, Riva Sanseverino E, Zizzo G. Smart renewable generation for an islanded system. Technical and economic issues of future scenarios. Energy, Vol. 39, pp. 196-204, 2012.

6. Alonso M, Amaris H, Alvarez-Ortega C. Integration of renewable energy sources in smart grids by means of evolutionary optimization algorithms. Expert Systems with Applications, 39 (5):5513-22, 2012.

https://doi.org/10.1016/j.eswa.2011.11.069

7. Al-Ali AR, El-Hag A, Bahadiri M, Harbaji M, Ali El Haj Y. Smart Home Renewable Energy Management System, Energy Procedia 2012, 12:120-6.

8. G. Aghajani and N. Ghadimi, Multi-objective energy management in a micro-grid, Energy Reports, Vol. 4, pp. 218-225, 2018.

https://doi.org/10.1016/j.egyr.2017.10.002

9. Q. Fu, A. Hamidi, A. Nasiri, V. Bhavaraju, S. B. Krstic, and P. Theisen. The Role of Energy Storage in a Microgrid Concept: Examining the opportunities and promise of microgrids, IEEE Electrification Magazine, Vol. 1, no. 2, pp. 21-29, 2013.

10. R. Bayindir, E. Hossain, and S. Vadi. The path of the smart grid - The new and improved power grid, Int. Smart Grid Work Certif. Program, October 2018.

11. Q. Jiang, M. Xue, and G. Geng. Energy management of microgrid in grid-connected and stand-alone modes, IEEE Trans. Power Syst. , Vol. 28, no. 3, pp. 3380-3389, 2013.

https://doi.org/10.1109/TPWRS.2013.2244104

12. Ahmad Khan, M. Naeem, M. Iqbal, S. Qaisar, and A. Anpalagan. A compendium of optimization objectives, constraints, tools and algorithms for energy management in microgrids, Renew. Sustain. Energy Rev., Vol. 58, pp. 1664-1683, 2016.

13. M. Stathopoulos, D. Zafirakis, K. Kavadias, and J. K. Kaldellis. The role of residential load-management in the support of RES-based power generation in remote electricity grids, Energy Procedia, Vol. 46, no. 5, pp. 281-286, October 2014.

14. MohammadiR, Rajabi MashhadiH. A game theory approach to distribution system reliability improvement based on customer requests. Iranian Journal of Electrical and Electronic Engineering, Vol. 15, No. 1, March 2019.

15. SoltaniZ, GhaljeheiM, Gharehpetian GB, Aalami HA. Integration of smartgrid technologies in stochastic multi-objective unit commitment: an economic emission analysis, Electrical Power and Energy Systems, Vol. 100, pp. 565-590, 2018.

https://doi.org/10.1016/j.ijepes.2018.02.028

16. Kenneth K. Zame, Christopher A. Brehm, Alex T. Nitica, Christopher L. Richard, Gordon D. Smart grid and energy storage: Policy recommendations, Renewable and Sustainable Energy Reviews, 2017.

17. Yu Y, Yang J, Chen B. Smart grids in China- a review. Energies 2012, Vol. 5, pp. 21-38.

18. A. Naamane and N.K. Msirdi. Towards a Smart Grid Communication, Energy Procedia, Vol. 83, pp. 428 433, December 2015.

19.Lu X, Lai J, Yu X, Wang Y, Guerrero JM. Distributed coordination of islanded microgrid clusters using a two-layer intermittent communication network. IEEE Trans, Vol 14, no. 9, pp. 3956-3969, Sep 2018.

20. Marzband M, Azarinejadian F, Savaghebi M, Pouresmaei IE, Guerrero JM, Lightbody G. Smart transitive energy frame working grid-connected multiple home microgrids under independent and coalition operations. Renew Energy, Elsevier, Vol. 126(C), pp. 95-106, 2018.

https://doi.org/10.1016/j.renene.2018.03.021

21. Muhammad Arshad Shehzad Hassan, Minyou Chen, Qiang Li, M. Ali Mehmood, Tingli Cheng, Bo Li. Microgrid Control and Protection State of the Art: A Comprehensive Overview, J. Electrical Systems Vol. 
14-2, pp. 148-164, 2018.

22. Wilsun $\mathrm{Xu}$, Konrad Mauch, and Sylvain Martel. An Assessment of Distributed Generation Islanding Detection Methods and Issues for Canada, CETC-Varennes 074 (TR) 411-INVERT, July 2004.

23. Vandoorn, T. L., Meersman, B., De Kooning, J. D. M., and Vandevelde, L. Directly-coupled synchronous generators with converter behavior in islanded microgrids, IEEE Trans. Power Syst., Vol. 27, No. 3, pp. 1395-1406, August 2012.

24. Ali Keyhani, Mohammad N. Marwali, and Min Dai. Integration of Green and Renewable Energy in Electric Power Systems, John Wiley \& Sons, 2010. https://doi.org/10.1002/9780470556771

25. Yeliz Yoldaş, Ahmet Önena, S.M. Muyeenb, Athanasios V. Vasilakosc, İrfan Alana. Enhancing smart grid with microgrid: Challenges and opportunities. Department of Electrical and Electronics Engineering, Abdullah Gul University, Kayseri, Turkey, Renewable and Sustainable Energy Reviews, Vol. 72, pp. 205-214, 2017.

26.Janez Potoc`nik. The European Technology Platform Smart Grids. Smart Grids: strategic deployment document for Europe's electricity networks of the future, Directorate-General for Research Sustainable Energy Systems, 2006.

27.E. Liu and J. Bebic. Distribution System Voltage Performance Analysis for High-Penetration Photovoltaics, NREL/SR-581-42298, February 2008.

28.P. Carvalho, P. Correia, and L. Ferreira. Distributed reactive power generation control for voltage rise mitigation in distribution networks, IEEE Transactions on Power Systems, Vol. 23, no. 2, pp. 766-772, May 2008.

29. A. Kumar and W. Gao. Optimal distributed generation location using mixed integer non-linear programming in hybrid electricity markets, IET Generation, Transmission and Distribution, Vol. 4, no. 2, pp. 281298, February 2010. https://doi.org/10.1049/iet-gtd.2009.0026

30.R. Dugan, T. McDermott, and G. Ball. Planning for distributed generation, IEEE Industry Applications Magazine, Vol. 7, no. 2, pp. 80-88, Apr 2001.

31.D. Q. Hung, N. Mithulananthan, and R. Bansal. Analytical expressions for DG allocation in primary distribution networks, IEEE Transactions on Energy Conversion, Vol. 25, no. 3, pp. 814-820, September 2010.

32. M. Akorede, H. Hizam, I. Aris, and M. Ab Kadir. Effective method for optimal allocation of distributed generation units in meshed electric power systems, IET Generation, Transmission Distribution, Vol. 5, no. 2, pp. 276 -287, February 2011.

https://doi.org/10.1049/iet-gtd.2010.0199

33. Rahbar K, Moghadam MRV, Reindl T, Panda SK. Shared energy storage management for renewable energy integration in smart grid, in Innovative Smart Grid Technologies Conference (ISGT), 2016 IEEE Power \& Energy Society; pp. 6-9 September 2016.

34. Walter CJ. High-value energy storage for the grid: a multidimensional look. Electr J, Vol. 23(10), pp. 59-71, 2010.

35. Makansi J. Energy Storage: The Sixth Dimension of the Electricity Production and Delivery Value Chain, 15 October 2012.

36.H. K. Nguyen, J. B. Song, and Z. Han. Distributed demand side management with energy storage in smart grid, IEEE Trans. Parallel Distrib. Syst., Vol. 26(12), pp. 3346-3357, 2015.

37. A. A. Thatte and L. Xie. Towards a unified operational value index of energy storage in smart grid environment, IEEE Trans. Smart Grid, Vol. 3, pp. 1418-1426, 2012.

38.H. Zhao, Q. Wu, S. Hu, H. Xu, and C. N. Rasmussen. Review of energy storage system for wind power integration support, Appl. Energy, Vol. 137, pp. 545-553, 2015.

39.K. Divya and J. stergaard. Battery energy storage technology for power systems-an overview, Electr. Power Syst. Res., Vol. 79(4), pp. 511-520, 2009. https://doi.org/10.1016/j.epsr.2008.09.017

40.M. Aneke and M.Wang. Energy storage technologies and real life applications- a state of the art review, Appl. Energy, Vol. 179, pp. 350-377, 2016.

41. Swapnil A, et. Al. Solar PV System for Electric Traction Application with Battery Backup. International Journal of Emerging Technologies in Engineering Research (IJETER), 7(1), pp. 1-4, 2019.

42.D. Dubal, O. Ayyad, V. Ruiz, and P. Gomez-Romero. Hybrid energy storage: The merging of battery and super capacitor chemistries, Chem. Soc. Rev., Vol. 44(7), pp. 1777-1790, 2015.

43. Mohd A, Ortjohann E, Schmelter A, Hamsic N, Morton D. Challenges in integrating distributed energy storage systems into future smart grid, in IEEE International Symposium on Industrial Electronics, 2008.

https://doi.org/10.1109/ISIE.2008.4676896

44. US Department of Energy, Benefits of Demand Response in Electricity Markets and Recommendations for achieving them, Report to the United States Congress, February 2006.

45. International Energy Agency. The Power to Choose Demand Response in Liberalized Electricity Markets, OECD, Paris, 2003.

46. M. Piette, O. Sezgen, D. Watson, N. Motegi, C. Shockman. Development and Evaluation of Fully Automated Demand Response in Large Facilities, Prepared For California Energy Commission, Public Interest Energy Research (PIER) Program, Vol. 30, March 2004.

47. O. Sezgen, C.A. Goldman, P. Krishnarao. Option value of electricity demand response, Energies, Vol. 32. pp. 108-119, 2007.

48.G. Aghajani and N. Ghadimi. Multi-objective energy management in a micro-grid, Energy Reports, Vol. 4, pp. 218-225, 2018.

https://doi.org/10.1016/j.egyr.2017.10.002 
49. Q. Fu, A. Hamidi, A. Nasiri, V. Bhavaraju, S. B. Krstic, and P. Theisen. The Role of Energy Storage in a Microgrid Concept: Examining the opportunities and promise of microgrids, IEEE Electrification Magazine, Vol. 1, no. 2, pp. 21-29, 2013.

50.Q. Fu, A. Hamidi, A. Nasiri, V. Bhavaraju, S. B. Krstic, and $\mathrm{P}$. Theisen. The Role of Energy Storage in a Microgrid Concept: Examining the opportunities and promise of microgrids, IEEE Electrif. Mag, Vol. 1, no. 2, pp. 21-29, 2013.

51.M. Stathopoulos, D. Zafirakis, K. Kavadias, and J. K. Kaldellis. The role of residential load-management in the support of RES-based power generation in remote electricity grids," Energy Procedia, Vol. 46, no. 10, pp. 281-286, 2014.

52. Motevasel, M.; Seifi, A.R. Expert energy management of a micro-grid considering wind energy uncertainty, Energy Convers. Manag. Vol. 83, pp. 58-72, 2014.

53.Sfikas, E.E, Katsigiannis, Y.A., Georgilakis,P.S. Simultaneous capacity optimization of distributed generation and storage in medium voltage microgrids. Int. J. Electr. Power Energy Syst., Vol. 67, pp. 101-113, 2015.

54. Alavi, S.A.; Ahmadian, A.; Aliakbar-Golkar, M. Optimal probabilistic energy management in a typical micro-grid based-on robust optimization and point estimate method, Energy Convers. Manag, Vol. 95, pp. 314-325, 2015.

55.Tenfen, D.; Finardi, E.C. A mixed integer linear programming model for the energy management problem of microgrids. Electr. Power Syst. Res., Vol. 122, pp. 19-28, 2015.

https://doi.org/10.1016/j.epsr.2014.12.019

56. Rezaei, N.; Kalantar, M. Stochastic frequency-security constrained energy and reserve management of an inverter interfaced islanded microgrid considering demand response programs. Int. J. Electr. Power Energy Syst. Vol. 69, pp. 273-286, 2015.

57.Aghajani, G.R.; Shayanfar, H.A.; Shayeghi, H. Presenting a multi-objective generation scheduling model for pricing demand response rate in micro-grid energy management. Energy Convers. Manag, Vol. 106, pp. 308-321, 2015.

58.A.; Sadeghi, M.; Aghaeic, J.; Heidari, A. Optimal operation of microgrids through simultaneous scheduling of electrical vehicles and responsive loads considering wind and PV units uncertainties. Renew. Sustain. Energy Rev., Vol. 57, pp. 721-739, 2016.

59. Q. Jiang, M. Xue, and G. Geng. Energy management of microgrid in grid-connected and stand-alone modes, IEEE Trans. Power Syst. , Vol. 28, no. 3, pp. 3380-3389, 2013.

60.A. Ahmad Khan, M. Naeem, M. Iqbal, S. Qaisar, and A. Anpalagan. A compendium of optimization objectives, constraints, tools and algorithms for energy management in microgrids, Renew. Sustain. Energy Rev., Vol. 58, pp. 1664-1683, 2016. https://doi.org/10.1016/j.rser.2015.12.259

61. Xiaoyu Wu, Yin Xu, Xiangyu Wu, Jinghan He, Josep M. Guerrero, Chen-Ching Liu, Kevin P. Schneider,and Dan T. Ton. A Two-Layer Distributed Control Method for Islanded Networked Microgrid Systems, October 2018.

62. Jasmine Kaur, Yog Raj Sood, and Rajnish Shrivastava. A two-layer optimization approach for renewable energy management of green microgrid in deregulated power sector, Journal of Renewable and Sustainable Energy, Vol. 9, 2017.

63. Xiaoqing Lu, Jingang Lai, Xinghuo Yu, Fellow, IEEE, Yaonan Wang, Josep M. Guerrero, Fellow, IEEE. Distributed Coordination of Islanded Microgrid Clusters Using a Two-layer Intermittent Communication Network, pp. 1551-3203, 2017.

64. Hajir Pourbabak, Tao Chen, Bowen Zhang, Wencong Su. Control and Energy Management System in Microgrids, 29 May 2017.

65. TinglongPan, HuiLiu, DinghuiWu, and ZeliangHao. Dual-Layer Optimal Dispatching Strategy for Microgrid Energy Management Systems considering Demand Response, Engineering Research Center of Internet of Things Technology, 8 July 2018.

66.J. Pascual, J. Barricarte, P. Sanchis, and L. Marroyo. Energy management strategy for a renewable-based residential microgrid with generation and demand forecasting, Appl. Energy, Vol. 158, pp. 12-25, 2015.

67.Y. Wang et al. Energy management of smart micro-grid with response loads and distributed generation considering demand response, J. Clean. Prod., Vol. 197, pp. 1069-1083, 2018.

https://doi.org/10.1016/j.jclepro.2018.06.271

68. Q. Jiang, M. Xue, and G. Geng, Energy management of microgrid in grid-connected and stand-alone modes, IEEE Trans. Power Syst., Vol. 28, no. 3, pp. 3380-3389, 2013.

69. C. Ju, P. Wang, L. Goel, and Y. Xu. A two-layer energy management system for microgrids with hybrid energy storage considering degradation costs, IEEE Trans. Smart Grid, vol. 9, no. 6, pp. 6047-6057, 2018.

70. S. Khemakhem, M. Rekik, and L. Krichen. Double layer home energy supervision strategies based on demand response and plug-in electric vehicle control for flattening power load curves in a smart grid, Energy, Vol. 167, pp. 312-324, 2019.

71. T. Pan, H. Liu, D. Wu, and Z. Hao. Dual-Layer Optimal Dispatching Strategy for Microgrid Energy Management Systems considering Demand Response, Math. Probl. Eng., Vol. 2018, pp. 1-14, 2018. https://doi.org/10.1155/2018/2695025

72.Elmer R. Magsino. Energy Monitoring System Incorporating Energy Profiling and Predictive Household Movement for Energy Anomaly Detection. International Journal of Emerging Technologies in Engineering Research (IJETER), 7(8), pp. 151-156, 2019. https://doi.org/10.30534/ijeter/2019/08782019 